\title{
Additional morphological notes and molecular-phylogenetic support for the distinct status of Deinostigma cicatricosa and D. minutihamata (Gesneriaceae)
}

\author{
Möller M. ${ }^{* 1}$, Bui H.Q. ${ }^{2}$, Linh L.T.M. ${ }^{2}$, Atkins H.J. ${ }^{1}$ \& D.J. Middleton ${ }^{3}$ \\ ${ }^{1}$ Royal Botanic Garden Edinburgh, 20A Inverleith Row, Edinburgh EH3 5LR, Scotland, U.K. \\ ${ }^{2}$ Institute of Ecology and Biological Resources, Vietnam Academy of Science and Technology, \\ 18 Hoang Quoc Viet Road, Cau Giay Dist., Ha Noi, Vietnam \\ ${ }^{3}$ Herbarium, Singapore Botanic Gardens, National Parks Board, 1 Cluny Road, 259569 Singapore \\ *E-mail: m.moeller@rbge.ac.uk
}

\begin{abstract}
During a recent molecular-phylogenetic revision of Deinostigma, material previously included in Chirita minutihamata D.Wood was assumed to belong to two different entities, Deinostigma minutihamata (D.Wood) D.J.Middleton \& H.J.Atkins for material collected in Vietnam and D. cicatricosa (W.T.Wang) D.J.Middleton \& Mich.Möller for material from China, although without supporting molecular evidence for the Vietnamese taxon. Here, we provide results in support of this decision in the form of a molecular phylogenetic analysis that includes material of D. minutihamata recently collected in Vietnam. This analysis shows that $D$. cicatricosa is more closely related to the other Chinese species, D. cyrtocarpa (D.Fang \& L.Zeng) Mich.Möller \& H.J.Atkins, than to the Vietnamese D. minutihamata. We also provide amended detailed descriptions of $D$. minutihamata and D. cicatricosa.
\end{abstract}

Keywords: China, Chirita cicatricosa, Chirita minutihamata, D. cicatricosa, Phylogeny, Taxonomy, Vietnam.

\section{Introduction}

Based on both molecular and morphological data, the genus Deinostigma W.T.Wang \& Z.Y.Li (Gesneriaceae) was recently expanded from being a monotypic genus, with D. poilanei (Pellegr.) W.T.Wang \& Z.Y.Li the only representative, to one that currently includes seven species (Möller et al., 2016).

Received: 13.11.2019; Revised \& Accepted: 19.03.2020

Published Online: 11.05 .2020
During the course of that study, the disjunct distribution of Chirita minutihamata D.Wood, as circumscribed by Wood (1974) and Wang et al. (1998), between central Vietnam and Guangxi in China was noted. While the plants were very similar in appearance, significant differences were also apparent, particularly in the longer, slender, more falcate fruits and the generally slightly larger flowers of the Chinese material. Together with the widely disjunct distribution, this led Möller et al. (2016) to treat them as separate species and the relevant new combinations were made: D. minutihamata (D.Wood) D.J.Middleton \& H.J.Atkins for the Vietnam material, and Deinostigma cicatricosa (W.T.Wang) D.J.Middleton \& Mich.Möller for the Chinese material. These combinations were made in anticipation of further studies, including through the use of molecular data when material of $D$. minutihamata became available, confirming that they were two distinct species.

During recent fieldwork by one of the authors, BHQ in Vietnam in June 2018, a collection was made in Quang Nam Province, Vietnam, conforming morphologically to D. minutihamata. Herbarium specimens and silica dried leaf material were collected. With this new material available for detailed comparative morphological and molecular phylogenetic studies, we are now able to investigate whether the recognition of $D$. cicatricosa as distinct from D. minutihamata is justified. 


\section{Materials and Methods}

\section{Plant materials}

Materials of $D$. minutihamata were collected from Quang Nam Province, Vietnam, in June 2018 (B.H.Quang Coll no. 218, N 1502'37.5', E $\left.108^{\circ} 02^{\prime} 19.9^{\prime \prime}, 692 \mathrm{~m}\right)$ for morphological and phylogenetic analyses (Fig. 1). Voucher specimens were deposited in the herbarium of the Institute of Ecology and Biological Resources, IEBR, Vietnam (HN, following the herbarium abbreviations of Thiers [continuously updated]).

For phylogenetic studies, six sequences of four species were downloaded from GenBank, $D$. cicatricosa and D. cyrtocarpa (D.Fang \& L.Zeng) Mich.Möller \& H.J.Atkins from China, and D. tamiana (B.L.Burtt) D.J.Middleton \& H.J.Atkins and D. poilanei from Vietnam. The outgroup consisted of 17 samples of 15 species in 9 genera implicated in the relationship spanning Deinostigma and Primulina Hance (Ranasinghe, 2017) (Table 1). The trees were rooted on Didymocarpus antirrhinoides A.Weber based on a comprehensive four plastid gene phylogeny (Ranasinghe, 2017).

\section{Total DNA extraction and PCR amplification}

Genomic DNA was extracted from leaf tissue ground in liquid nitrogen according to the CTAB protocol of Doyle and Doyle (1990). The quality of DNA was determined using 1.0\% agarose gels. The purified genomic DNA was quantified using a BioRad Smartspec 3000 UVVis spectrophotometer (California, USA).

Sequences of the nuclear ribosomal internal transcribed spacers (ITS) and the plastid trnL-F intron spacer $(t r n \mathrm{~L}-\mathrm{F})$ were PCR-amplified using primers: '5P' (5'-GGA AGG AGA AGT CGT AAC AAG G-3') and '8P' (5'-CAC GCT TCT CCA GAC TAC A-3') (Möller \& Cronk, 1997) and 'c' (5'-CGA AAT CGG TAG ACG CTA-3') and ' $\mathrm{f}$ ' (5'ATT TGA ACT GGT GAC ACG AG3') (Taberlet et al., 1991). The PCR reaction mixture contained $15 \mu$ l Hotstart PCR Mastermix
(Promega, USA), $1 \mu \mathrm{l}$ forward and reverse primers $(10 \mu \mathrm{M}), 2 \mu \mathrm{l}$ DNA template and $\mathrm{d}_{2} \mathrm{O}$ up to a volume of $30 \mu$ l. The PCR programme settings for ITS were: $95^{\circ} \mathrm{C}$ for $5 \mathrm{~min}$, followed by 35 cycles of $95^{\circ} \mathrm{C}$ for $35 \mathrm{~s}, 55^{\circ} \mathrm{C}$ for $45 \mathrm{~s}$ and $72^{\circ} \mathrm{C}$ for $60 \mathrm{~s}$, and finished with $72^{\circ} \mathrm{C}$ for $3 \mathrm{~min}$; for $\operatorname{trn} \mathrm{L}-\mathrm{F}$ it was: $95^{\circ} \mathrm{C}$ for $5 \mathrm{~min}$, followed by 35 cycles of $95^{\circ} \mathrm{C}$ for $35 \mathrm{~s}, 50^{\circ} \mathrm{C}$ for $30 \mathrm{~s}$ and $72^{\circ} \mathrm{C}$ for $45 \mathrm{~s}$, and finished with $72^{\circ} \mathrm{C}$ for $3 \mathrm{~min}$. Electrophoresis of $5 \mu \mathrm{l}$ PCR product on a $1.5 \%$ agarose gel in TEA buffer $(1 \mathrm{~h}, 100 \mathrm{~V})$ was carried out to check for amplification success and quality. PCR products were purified using ExoSAP-IT (Thermo Fisher Scientific, Buckinghamshire, UK) following the manufacturer's protocol. Sequencing was performed at the Apical Scientific Sdn Bhd sequencing service (Selangor, Malaysia). Sequence clean-up and sequence assembly, was carried out by the Department of Molecular Systematics and Conservation Genetics (IBER).

\section{Phylogenetic analysis}

The sequences downloaded from GenBank and the newly acquired data were assembled in two matrices, one for ITS and one for trnL-F and included 24 samples each. The sequences were aligned online in MAFFT (v.7 online (https:// mafft.cbrc.jp/alignment/server/) (Kuraku et al., 2013; Katoh et al., 2017) and adjusted manually. The two matrices were tested for phylogenetic incongruences with the incongruence length difference test (ILD) implemented in PAUP* v.4.0a163 (Swofford, 2002) as the partition homogeneity test, and was run for 100 replicates.

The data matrices were analysed by maximum parsimony (MP) and Bayesian Inference (BI) in PAUP and MrBayes v.3.2.6 (Ronquist \& Huelsenbeck, 2003; Ronquist et al., 2012). Parsimony trees were obtained from 10,000 random addition sequence trees that were optimized using MulTrees, SteepestDescent, and Tree-BisectionReconnection (TBR). Node support was estimated with 10,000 bootstrap replicates, each comprising 


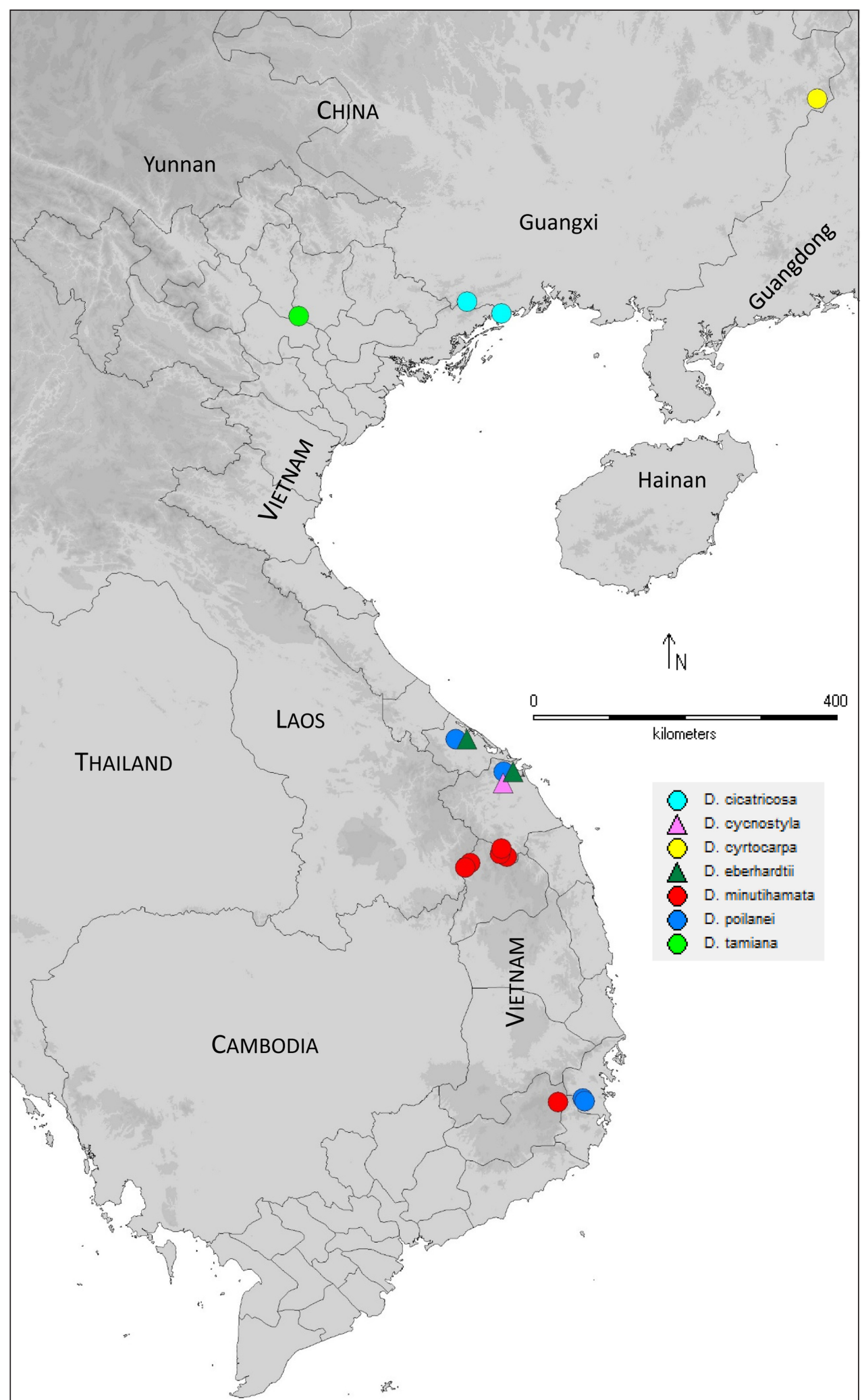

Fig. 1. Known distribution points of Deinostigma species. Those included in the phylogenetic analyses are shown as circles and those not included as triangles: D. cicatricosa (W.T.Wang) D.J.Middleton \& Mich.Möller (light blue circles) and D. cyrtocarpa (D.Fang \& L.Zeng) Mich.Möller \& H.J.Atkins (yellow circle) in Guangxi, China, and D. tamiana (B.L.Burtt) D.J.Middleton \& H.J.Atkins (light green circle), D. minutihamata (D.Wood) D.J.Middleton \& H.J.Atkins (red circles), D. poilanei (Pellegr.) W.T.Wang \& Z.Y.Li (dark blue circles), and the unsampled D. cycnostyla (B.L.Burtt) D.J.Middleton \& H.J.Atkins (pink triangle), and D. eberhardtii (Pellegr.) D.J.Middleton \& H.J.Atkins (dark green triangles). 
Table 1. List of samples included in the molecular phylogenetic analyses including country of origin, collection information, voucher deposition and GenBank accession numbers for ITS and trnLF

\begin{tabular}{|c|c|c|c|c|c|}
\hline Species & Country & Collection & Deposited & ITS & $\operatorname{trn} \mathrm{LF}$ \\
\hline $\begin{array}{l}\text { Agalmyla clarkei (Elmer) } \\
\text { B.L.Burtt }\end{array}$ & Indonesia & $\begin{array}{l}\text { RBGE-Philippine National } \\
\text { Herbarium Expedition } 1999 \\
\text { (P99) } 13\end{array}$ & E & FJ501360 & FJ501540 \\
\hline $\begin{array}{l}\text { Agalmyla paucipilosa Hilliard } \\
\text { \& B.L.Burtt }\end{array}$ & Indonesia & P. Smith \& L. Galloway 261 & E & HQ632990 & HQ632893 \\
\hline $\begin{array}{l}\text { Deinostigma cicatricosa } \\
\text { (W.T.Wang) D.J.Middleton } \\
\text { \& Mich.Möller }\end{array}$ & China & $\begin{array}{l}\text { M. Moeller \& Y.G. Wei } \\
\text { MMO07-1148 }\end{array}$ & IBK/E & KU990890 & KU990886 \\
\hline $\begin{array}{l}\text { Deinostigma cicatricosa } \\
\text { (W.T.Wang) D.J.Middleton } \\
\text { \& Mich.Möller }\end{array}$ & China & W.B. Xu s.n. & IBK & JX506925 & JX506817 \\
\hline $\begin{array}{l}\text { Deinostigma cyrtocarpa } \\
\text { (D.Fang \& L.Zeng) } \\
\text { Mich.Möller \& H.J.Atkins }\end{array}$ & China & $\begin{array}{l}\text { M. Moeller \& Y.G. Wei } \\
\text { MMO 06-908 }\end{array}$ & IBK/E & KU990889 & KU990885 \\
\hline $\begin{array}{l}\text { Deinostigma cyrtocarpa } \\
\text { (D.Fang \& L.Zeng) } \\
\text { Mich.Möller \& H.J.Atkins }\end{array}$ & China & W.B. Xu s.n. & IBK & JX506885 & JX506777 \\
\hline $\begin{array}{l}\text { Deinostigma minutihamata } \\
\text { (D.Wood) D.J.Middleton } \\
\text { \& H.J.Atkins }\end{array}$ & Vietnam & B.H. Quang 218 & $\mathrm{HN}$ & MT066216 & MT075730 \\
\hline $\begin{array}{l}\text { Deinostigma poilanei (Pellegr.) } \\
\text { W.T.Wang \& Z.Y.Li }\end{array}$ & Vietnam & R. Rybkova HB222 & - & KU990892 & KU990888 \\
\hline $\begin{array}{l}\text { Deinostigma tamiana } \\
\text { (B.L.Burtt) D.J.Middleton } \\
\text { \& H.J.Atkins }\end{array}$ & Vietnam & $\begin{array}{l}\text { Soviet-Vietnam Expedition } \\
\text { (Liberec B.G., Czech Republic } \\
\text { \& St.Petersburg B.G) 01/114 }\end{array}$ & E & KU990891 & KU990887 \\
\hline $\begin{array}{l}\text { Didymocarpus antirrhinoides } \\
\text { A.Weber }\end{array}$ & Malaysia & $\begin{array}{l}\text { K. Jong } 9009 \\
\text { (RBGE cult. 19650167) }\end{array}$ & $\mathrm{E}$ & DQ912671 & FJ501513 \\
\hline $\begin{array}{l}\text { Didymostigma obtusum (Clarke) } \\
\text { W.T.Wang }\end{array}$ & China & M. Moeller et al. 08-1310 & E & HQ632971 & HQ632875 \\
\hline $\begin{array}{l}\text { Didymostigma trichanthera } \\
\text { C.X.Ye \& X.G.Shi }\end{array}$ & China & M. Moeller et al. 08-1335 & $\mathrm{E}$ & HQ632972 & HQ632876 \\
\hline $\begin{array}{l}\text { Hemiboea fangii Chun } \\
\text { ex Z.Y.Li }\end{array}$ & China & M. Moeller et al. 08-1284 & $\mathrm{E}$ & HQ632979 & HQ632882 \\
\hline $\begin{array}{l}\text { Hemiboea longgangensis } \\
\text { Z.Y.Li }\end{array}$ & China & Y.G. Wei 07550 & IBK & HQ632986 & HQ632889 \\
\hline $\begin{array}{l}\text { Metapetrocosmea peltata } \\
\text { (Merr. \& Chun) W.T.Wang }\end{array}$ & China & Y.G. Wei 07-702 & IBK & HQ632968 & HQ632872 \\
\hline $\begin{array}{l}\text { Oreocharis acaulis (Merr.) } \\
\text { Mich.Möller \& A.Weber }\end{array}$ & China & M. Moeller et al. 08-1328 & E & HQ633012 & HQ632916 \\
\hline Oreocharis henryana Oliv. & China & M. Moeller et al. 10-1691 & $\mathrm{E}$ & JF697574 & JF697586 \\
\hline Petrocodon dealbatus Hance & China & $\begin{array}{l}\text { Xie Qingjian J-042 } \\
\text { (US 422841) }\end{array}$ & US & FJ501358 & FJ501537 \\
\hline $\begin{array}{l}\text { Petrocodon dealbatus var. } \\
\text { denticulatus (W.T.Wang) } \\
\text { W.T.Wang }\end{array}$ & China & Y.G. Wei 2010-03 & IBK & JF697578 & JF697590 \\
\hline
\end{tabular}


a single random addition sequence tree with the same settings as above.

Bayesian inference analyses were implemented using substitution models selected separately for the ITS spacers, the $5.8 \mathrm{~S}$ gene and $\operatorname{trn} \mathrm{L}-\mathrm{F}$ in MrModelTest2_64bit (Nylander, 2004), under the Akaike Information Criterion (Akaike, 1974), and were $G T R+G$ for the ITS spacers, SYM $+\mathrm{I}+\mathrm{G}$ for the ITS-5.8S gene, and GTR+I for tr $n \mathrm{~L}-\mathrm{F}$. Two independent runs of four Markov Chain Monte Carlo (MCMC) chains were run for one million generations, sampling every 1,000 generations. A stop-rule was implemented when the average standard deviation of split frequencies reached 0.01 , and after removing the burn-in set to $10 \%$ of the sampled trees, a majority rule consensus tree was built from the remaining sampled trees, providing also the posteriori probabilities for each node.

\section{Results}

The ILD test returned a maximum value $(P=1.0)$ which indicated that no incongruence between the data sets existed. As such the phylogenetic analyses were performed on combined data. The combined matrix had 1,583 characters of which 1,098 were constant (69.4\%), 157 variable (9.9\%) and 328 parsimony-informative (20.7\%). The MP analysis retained one most parsimonious tree of 1,068 steps length, a consistency index (CI) of 0.6442 and retention index (RI) of 0.6933 that was fully resolved. Convergence of the BI runs was satisfactory (Appendix 1). The topology of the MP and $\mathrm{BI}$ trees were identical except for two branches that collapsed in the latter that also had no support in the MP analysis (Figs. 2 \& 3).

In both analyses, Deinostigma was monophyletic with high branch support (MPBS $=85 \%$; $\mathrm{BIPP}=0.97)$. It is sister to Metapetrocosmea W.T.Wang (MPBS=100\%; BIPP=1) and distant from the Primulina samples that were sister to the Petrocodon Hance samples with very high branch support $(\mathrm{MPBS}=99 \%$; BIPP=1). The samples of the Chinese species of Deinostigma, D. cyrtocarpa and $D$. cicatricosa, are sister and monophyletic (MPBS=62\%; BIPP=0.76). The species pair D. tamiana and $D$. poilanei from Vietnam are also sister (MPBS=99\%; BIPP=1). The sample of $D$. minutihamata from Vietnam is sister to the two Chinese species in the MP analysis (MPBS $=<50 \%$ ), and on a polytomy with these and the clade of the sister pair D. tamiana and D. poilanei in the BI analysis.

\section{Discussion}

Our molecular phylogenetic analyses confirm the suggestion by Möller et al. (2016) that the collections subsumed under Chirita minutihamata by Wood (1974) and Wang et al. (1998) belong indeed to two different species, since the material from China, now regarded as D. cicatricosa, is sister to D. cyrtocarpa with reasonable support, rather than to the Vietnamese specimen of $D$. minutihamata (Figs. $2 \& 3$ ). This makes geographic sense since the two Chinese species are more closely related to each other than to the Vietnamese species (Figs. 13). The morphological case to support the separate status of D. minutihamata and D. cicatricosa has been made above and previously concerning the corolla size and fruit shape (Möller et al., 2016). Amended descriptions are provided below. From these, corolla colour, filament indumentum and fruit size can be added to the list of characters differentiating the two species. A summary of the main morphological characters differentiating all three species is provided in Table 2 and photographic images are provided in Fig. 4.

The phylogenies we reconstruct here do not completely reflect the distribution of Deinostigma species across the range of the genus, since the strongly supported sister pair in Vietnam, D. tamiana and $D$. poilanei, are rather disjunct in the north on the one hand and the centre and south of Vietnam on the other. However, these disjunctions may represent an artefact of undersampling, and 


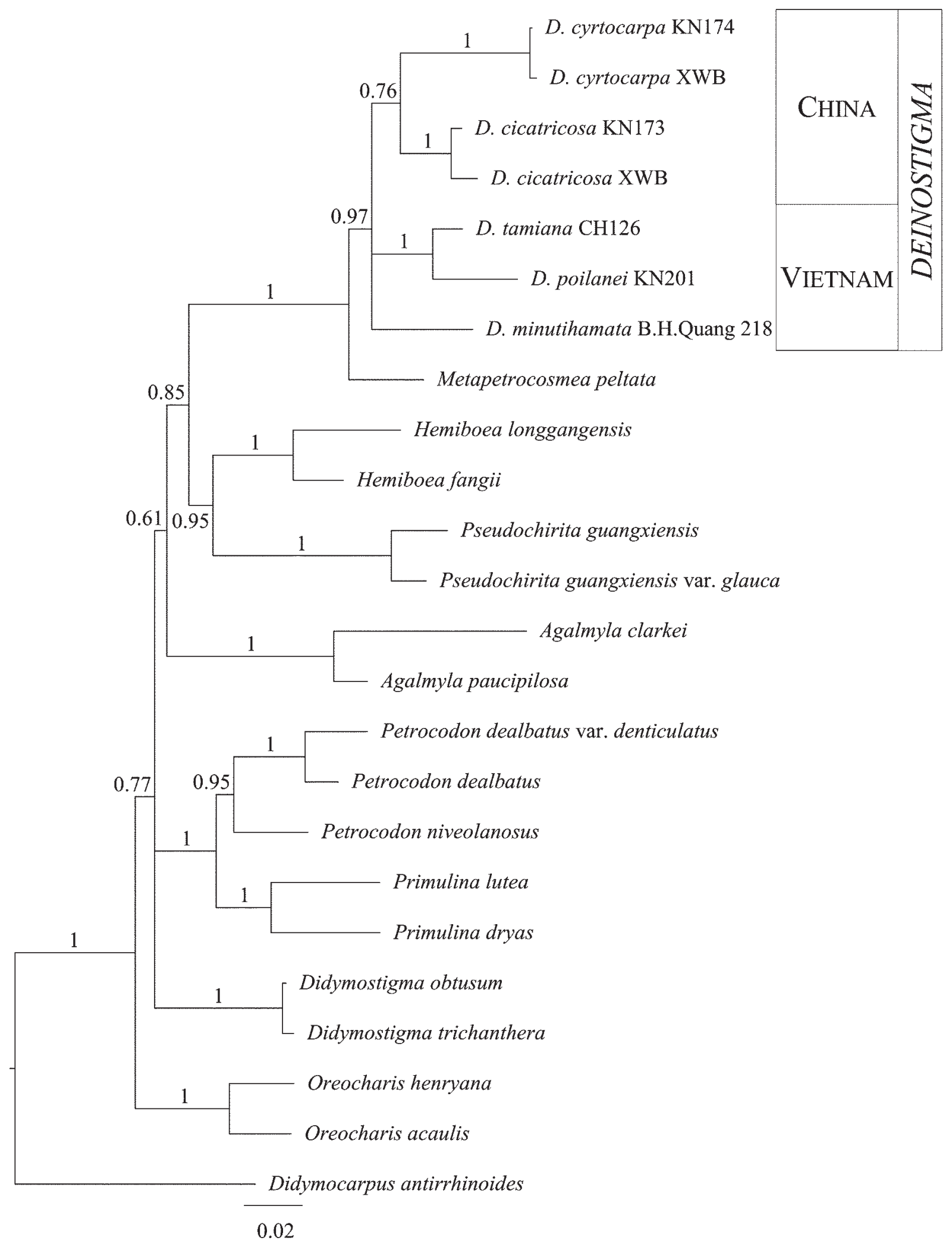

Fig. 2. Single most parsimonious tree of 1068 steps length $(\mathrm{Cl}=0.6442 ; \mathrm{Rl}=0.6933)$, based on combined ITS and trnL-F data for the relationships among Deinostigma species. Bootstrap values along the branches. * denotes values $<50 \%$. 
additional fieldwork may yet uncover more distribution points for some of the species, or as yet undiscovered species. Vietnam is known to be undercollected (Middleton et al., 2019) and the consequences of low collection density have been demonstrated in other Gesneriaceae genera, such as Oreocharis Benth., which until recently was only known from one species in Vietnam, but which in the last two years has increased to eight species due to new collections from recent expeditions (Möller et al., 2018). Most of these Oreocharis species are local endemics and only one, O. aurea Dunn, is widespread in southern Yunnan and northern Vietnam (Chen et al., 2018). Such patterns of high levels of narrow endemism and rarer widespread distributions within a genus are common in Gesneriaceae (Middleton et al., 2019) and may also be present in Deinostigma, where most species have a narrow distribution and only D. minutihamata and $D$. poilanei appear to be more widespread (Fig. 1). However, more fieldwork is needed, particularly in Vietnam and perhaps also in Laos, to obtain a complete picture of the distribution of Deinostigma species.

Deinostigma cicatricosa (W.T.Wang) D.J.Middleton \& Mich.Möller, Gard. Bull. Singapore 68(1): 155 (2016). Chirita cicatricosa
W.T.Wang, Bull. Bot. Res., Harbin 1(4): 69 (1981). Type: CHINA, Guangxi, Dongxing, Banba Commune, Renbei, 03.10.1976, D. Fang et al. 1525 (holo GXMI [GXMI050619!]).

Fig. 4 a, b

Vernacular name: 多痕奇柱芭苔, Duō hén qí zhù jù tái(Chinese)

Perennial herbs. Stems decumbent or erect, densely pubescent with hairs of varying lengths, the longer hairs mostly glandular but with scattered eglandular hairs and small hooked hairs, glabrescent with age, peg-like bases of fallen leaves persistent. Leaves alternate, crowded towards branch apices, internodes 3-8 mm; petioles 1.3-6 cm long, densely pubescent with longer glandular hairs and short hooked hairs; blade ovate to elliptic, 1.8-7.5 × 1.4$4.3 \mathrm{~cm}, 0.9-2.2$ times as long as wide, base cuneate to subcordate, apex short acuminate, margins crenate, secondary veins $4-5$ on each side of midrib, sparsely to densely pubescent above and beneath. Inflorescences axillary, few-flowered, sometimes only 1-flowered, to $10 \mathrm{~cm}$ long, all axes with longer glandular hairs and short hooked hairs; peduncle $4.5-5 \mathrm{~cm}$ long; bracts ovate, c. $7.5 \times 3.2 \mathrm{~mm}$, apex acuminate; pedicels $6-9 \mathrm{~mm}$ long. Calyx 5-lobed; lobes divided to base, narrowly elliptic, 10.5-13 × 2.1-2.4 mm, apex acuminate, densely pubescent as on inflorescence axes. Corolla infundibuliform, 45-

Table 2. Comparison of characteristics of three species in Deinostigma, D. cyrtocarpa, D. cicatricosa and D. minutihamata.

\begin{tabular}{|c|c|c|c|}
\hline Characters & $\begin{array}{l}\text { D. cyrtocarpa } \\
\text { (D.Fang \& L.Zeng) } \\
\text { Mich.Möller \& } \\
\text { H.J.Atkins }\end{array}$ & $\begin{array}{l}\text { D. cicatricosa } \\
\text { W.T.Wang) } \\
\text { D.J.Middleton \& } \\
\text { Mich.Möller }\end{array}$ & $\begin{array}{l}\text { D. minutihamata } \\
\text { (D.Wood) } \\
\text { D.J.Middleton \& } \\
\text { H.J.Atkins }\end{array}$ \\
\hline Leaf & $3-15 \times 1.5-6.5 \mathrm{~cm}$ & $1.8-7.5 \times 1.4-4.3 \mathrm{~cm}$ & $2.6-10.2 \times 1.8-4 \mathrm{~cm}$ \\
\hline Corolla length & $3.3-5.5 \mathrm{~cm}$ & $4.5-5.8 \mathrm{~cm}$ & $3.7-5.2 \mathrm{~cm}$ \\
\hline Corolla colour & Dark purple & Dark purple & $\begin{array}{l}\text { Pale purple to violet, with a } \\
\text { few darker lines ventrally }\end{array}$ \\
\hline Filament indumentum & $\begin{array}{l}\text { Glandular puberulent, } \\
\text { densely bearded apically }\end{array}$ & Densely long pubescent & $\begin{array}{l}\text { Glabrous except sparsely } \\
\text { pubescent at apex }\end{array}$ \\
\hline Ovary length & $7-9 \mathrm{~mm}$ & c. $13 \mathrm{~mm}$ & c. $13 \mathrm{~mm}$ \\
\hline Fruit position & $\begin{array}{l}\text { Plagiocarpic, at } \pm 90^{\circ} \text { angle } \\
\text { to pedicel }\end{array}$ & $\begin{array}{l}\text { Orthocarpic, } \pm \text { straight in } \\
\text { relation to pedicel }\end{array}$ & $\begin{array}{l}\text { Orthocarpic, } \pm \text { straight in } \\
\text { relation to pedicel }\end{array}$ \\
\hline Fruit shape and size & Straight, $1.5-2 \mathrm{~cm}$ long & Curved, $4.5-5 \mathrm{~cm}$ long & Straight, 2-2.3 cm long \\
\hline Fruit dehiscence & $\begin{array}{l}\text { Predominantly loculicidally } \\
\text { along the upper suture }\end{array}$ & $\begin{array}{l}\text { Loculicidally dehiscing } \\
\text { along both sutures into } \\
2 \text { valves }\end{array}$ & $\begin{array}{l}\text { Loculicidally dehiscing } \\
\text { along both sutures into } \\
2 \text { valves }\end{array}$ \\
\hline
\end{tabular}




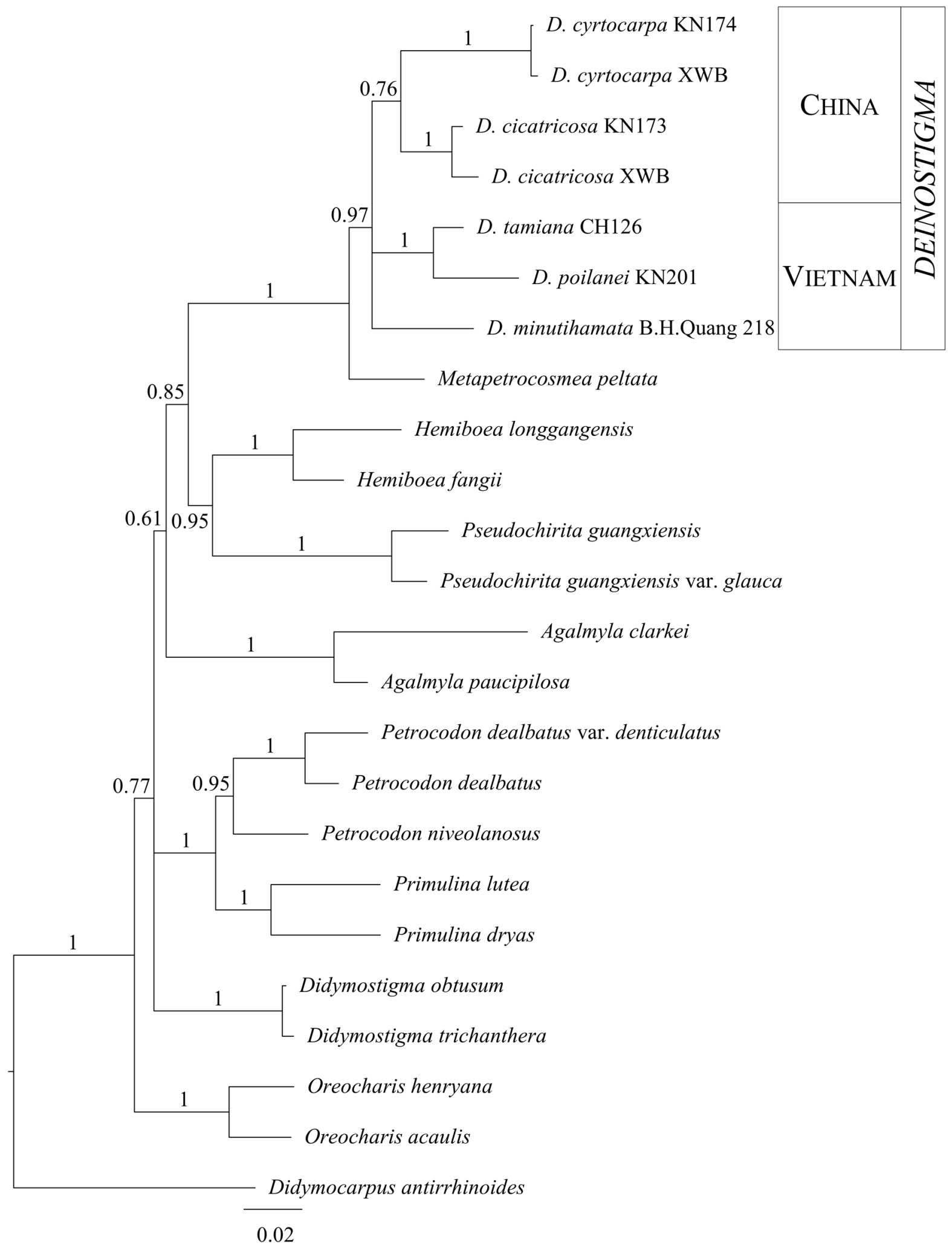

Fig. 3. Bayesian inference majority rule consensus tree with average branch lengths based on combined ITS and trnL-F data for the relationships among Deinostigma species. Posterior probabilities along the branches. 
$58 \mathrm{~mm}$ long; dark purple, tube 33-37.5 mm long, lobes orbicular, apices rounded; upper lobes 7-9 $\times$ 7-9 mm, lateral lobes $c .8 \times 10-11 \mathrm{~mm}$, lower lobe $8-9.5 \times 9.2-11.5 \mathrm{~mm}$, pubescent outside with glandular hairs, glabrous inside. Fertile stamens 2; filaments slightly curved, 10-12 mm long, densely long pubescent; anthers coherent, 1.5-2 × 3.5-5.5 $\mathrm{mm}$, densely pubescent; staminodes $3,8.5-10 \mathrm{~mm}$ long, densely pubescent. Disc 5-lobed, c. $1 \mathrm{~mm}$ high. Ovary c. $13 \mathrm{~mm}$ long, densely glandular pubescent; style c. $18 \mathrm{~mm}$ long, densely glandular pubescent; stigma chiritoid, lower lip 2-lobed, $c$. $5.5 \mathrm{~mm}$ long. Mature capsule curved, $4.5-5 \mathrm{~cm}$ long. Seeds not seen.

Flowering \& fruiting: Flowering from OctoberDecember and fruiting from November.

Habitat: Growing in montane forests.

Distribution: Endemic to China (Guangxi).

Specimen examined: CHINA, Guangxi (as Kwangtung on label, Kwangtung-Tonkin border), Fang Cheng district, Kung Ping Shan and vicinity, semi-woody, growing in thicket, 25-30.08.1936, W.T.Tsang 26711 (E [E00627703]).

\section{Deinostigma minutihamata (D.Wood)} D.J.Middleton \& H.J.Atkins, Gard. Bull. Singapore 68(1): 158. 2016. Chirita minutihamata D.Wood, Notes Roy. Bot. Gard. Edinburgh 31: 370. 1972. Primulina minutihamata (D.Wood) Mich.Möller \& A.Weber, Taxon 60: 783. 2011. Type: VIETNAM, Kon Tum, Dak Glei district, Ngok Pa Not, 2300 m, 12.12.1946, E. Poilane 35803 (holo P [P00602518!] isotype P [P00602519!]). Fig. 4e-j

Vernacular name: Báo xuân móc nhỏ(Vietnamese).

Subshrub or perennial herbs, to $40 \mathrm{~cm}$ tall. Stems decumbent, branched, densely pubescent with hairs of varying lengths, the longer hairs mostly eglandular but with scattered glandular hairs and small hooked hairs, glabrescent with age, peg-like bases of fallen leaves persistent. Leaves alternate, crowded towards branch apices, internodes 3-6 $\mathrm{mm}$; petioles $1.7-4 \mathrm{~cm}$ long, densely pubescent with glandular and eglandular hairs; blade ovate to elliptic, $2.6-10.2 \times 1.8-4 \mathrm{~cm}, 1.2-3$ times as long as wide, base cuneate, rarely to obtuse, apex short acuminate, margins weakly crenate, secondary veins $4-5$ on each side of midrib, densely pubescent above and beneath. Inflorescences axillary, fewflowered, sometimes only 1-flowered, to $8.2 \mathrm{~cm}$ long, all axes with longer glandular and eglandular hairs and shorter hooked hairs; peduncle to $2.7 \mathrm{~cm}$ long; bracts ovate, c. $13 \times 7 \mathrm{~mm}$, apex acuminate; pedicels 5-28 mm long. Calyx 5-lobed; lobes divided to base, narrowly ovate, $16-17 \times 2-2.2 \mathrm{~mm}$, apex acuminate, densely pubescent as on inflorescence axes. Corolla infundibuliform, 37$52 \mathrm{~mm}$ long; pale blue to violet with few darker lines ventrally, lobes orbicular, apices rounded; tube 28-35 mm long; upper lobes c. $9 \times 7 \mathrm{~mm}$, lateral lobes $c .5 \times 7 \mathrm{~mm}$, lower lobe $c .7 \times 7 \mathrm{~mm}$, pubescent outside with glandular and eglandular hairs, glabrous inside. Fertile stamens 2; filaments slightly curved, c. $11.6 \mathrm{~mm}$ long, glabrous except sparsely pubescent at apex; anthers coherent, 1.4-2 × 3-5 $\mathrm{mm}$, densely pubescent; staminodes 3, c. $8 \mathrm{~mm}$ long, pubescent at apex. Disc not seen. Ovary c. $13 \mathrm{~mm}$ long, densely glandular pubescent; style $c .15 \mathrm{~mm}$ long, densely glandular pubescent; stigma chiritoid, lower lip 2-lobed, c. $3 \mathrm{~mm}$ long. Capsules narrowly fusiform, straight, $2-3.5 \mathrm{~cm}$ long, sparsely pubescent. Seeds $0.4-0.5 \times 0.15-0.2 \mathrm{~mm}$.

Flowering \& fruiting: Flowering from April-June and fruiting from July-December.

Habitat: Growing on rocks in primary forest.

Distribution: Endemic to Vietnam.

Specimens examined: VIETNAM, Kon Tum, Dak Glei district, Massif du Ngok Pan, 2300 m, 12.12.1946, Poilane 35781 (P [P03884219]; NW slope of Ngoc Linh mountain system above Long Nam village, 1700-1900 m, 04.04.1995, Averyanov, N.T. Hiep, P.K. Loc VH1165 (P [P03884218], E [E00267299], HN [HN0000031083]); W slope of Ngoc Linh mountain system on elevation to Ngoc Gua peak, 1900-2000 m, 10.04.1995, Averyanov, N.T. Hiep, P.K. Loc VH1316 (P [P03884217], HN [HN0000031082]). Lam Dong, Lac Duong district, Da Chay municipality, $29 \mathrm{~km}$ to NE from Dalat city, 2150 m, 01.05.1997, 

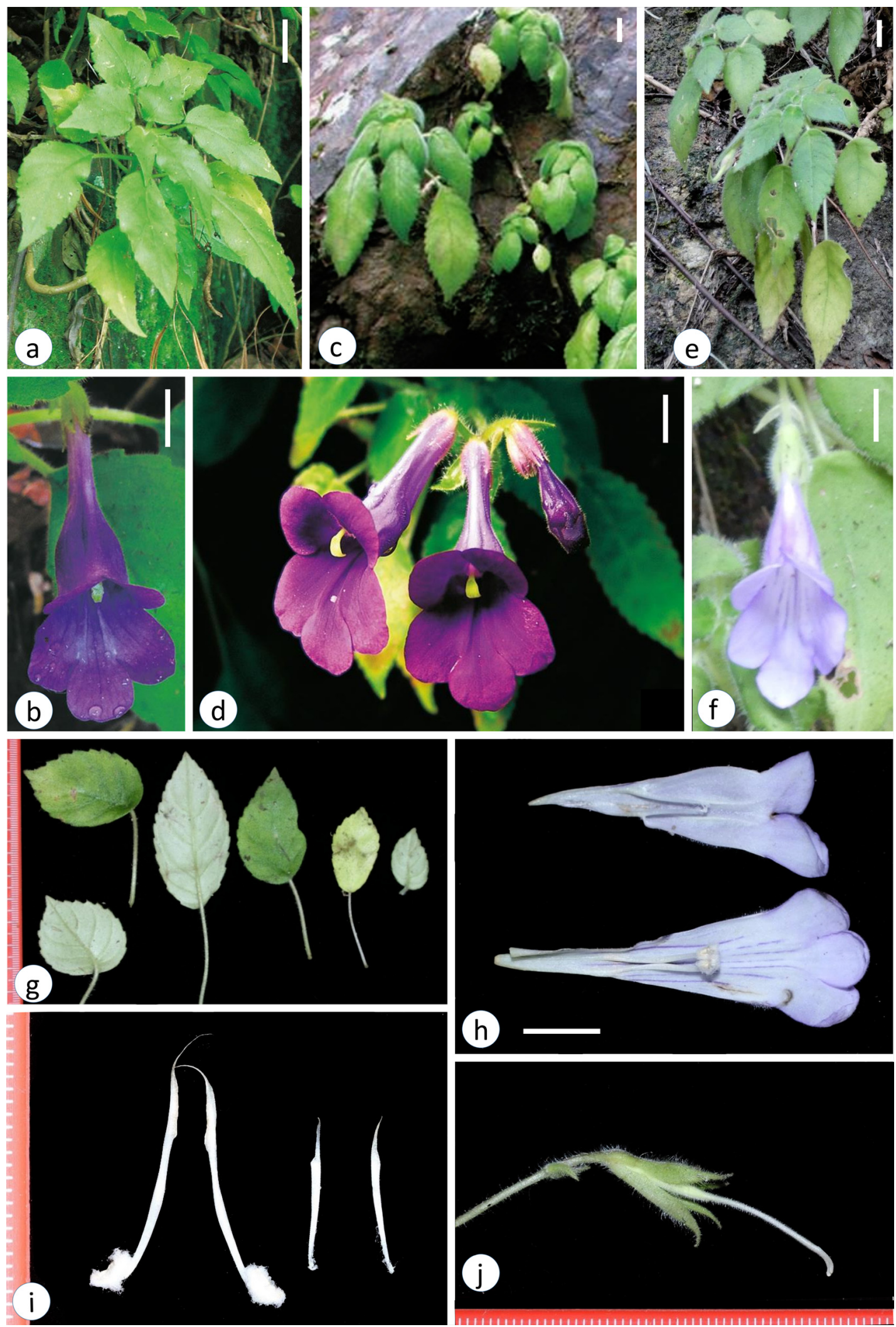

Fig. 4. Photographic images of Deinostigma cicatricosa (W.T.Wang) D.J.Middleton \& Mich.Möller (a, b), its phylogenetically closest relative D. cyrtocarpa (D.Fang \& L.Zeng) Mich.Möller \& H.J.Atkins (c, d), and D. minutihamata (D.Wood) D.J.Middleton \& H.J.Atkins (e-j): a, c, e. Habit; b, d, f. Flowers; g. Adaxial and abaxial side of leaves; h. Cut open flower; i. Stamens (left) and staminodes (right); j. Calyx and pistil. a, c, e. scale bars $=2 \mathrm{~cm}, \mathrm{~b}, \mathrm{~d}, \mathrm{f}, \mathrm{h}$ scale bars $=1 \mathrm{~cm}, \mathrm{~g}-\mathrm{j}$ scales in $\mathrm{mm}$ (photos a \& $\mathbf{c}$ by M. Möller; $\mathbf{b} \& \mathbf{d}$ by Yi-Gang Wei; $\mathbf{e}-\mathbf{j}$ by H.Q. Bui). 
Averyanov, N.T. Hiep, P.K. Loc VH4492 (HN [HN0000031034]). Quang Nam, Nam Tra My district, Tra Linh commune, Tra Cang village, $\mathrm{N}$ 1502'37.5", E 10802'19.9", 692 m, 18.06.2018, Quang 218 (HN).

\section{Acknowledgements}

We thank the director of IBER and the curators of $\mathrm{HN}$ and $\mathrm{P}$ for the opportunity to examine the voucher specimens. This research has been funded by the Vietnam National Foundation for Science and Technology Development (NAFOSTED) under grant number 106.03-2017.300 (B.H.Q). We thank Prof. Wei Yi-Gang, IBK, for providing photographic images of Deinostigma species occurring in China, and Dr. Wen Fang, IBK, for providing the Chinese vernacular name. We would like to acknowledge two anonymous reviewers for helpful comments on the manuscript. The Royal Botanic Garden Edinburgh is supported by the Rural and Environment Science and Analytical Services Division (RESAS) of the Scottish Government.

\section{Literature Cited}

AKAIKE H. 1974. A new look at the statistical model identification. IEEE Transactions on Automation Control 19: $716-723$.

CHEN W.H., NGUYEN Q.H., CHEN R.Z., NGUYEN T.H., NGUYEN S.K., NGUYEN V.T., MÖLLER M., MIDDLETON D.J. \& Y.M. SHUI 2018. Two new species of Oreocharis (Gesneriaceae) from Fan Si Pan, the highest mountain in Vietnam. PhytoKeys 94: 95-106. https://doi.org/10.3897/phytokeys.94.21329

DOYLE J.J. \& J.L. DOYLE 1990. Isolation of plant DNA from fresh tissue. Focus 12: 13-15.

KATOH K., ROZEWICKI J. \& K.D. YAMADA 2017. MAFFT online service: multiple sequence alignment, interactive sequence choice and visualization. Briefings in Bioinformatics 20(4): 1160-1166. https://doi.org/10.1093/ bib/bbx108

KURAKU S., ZMASEK C.M., NISHIMURA O. \& K. $\mathrm{KATOH}$ 2013. aLeaves facilitates on-demand exploration of metazoan gene family trees on MAFFT sequence alignment server with enhanced interactivity. Nucleic Acids Research 41(W1): W22-W28. https://doi.org/10.1093/nar/gkt389

MIDDLETON D.J., ARMSTRONG K., BABA Y., BALSLEV H., CHAYAMARIT K., CHUNG R.C.K.,
CONN B.J., FERNANDO E.S., FUJIKAWA K., KIEW R., LUU H.T., MU MU AUNG, NEWMAN M.F., NOBUYUKI T., TAGANE S., THOMAS D.C., TRAN T.B., UTTERIDGE T.M.A., VAN WELZEN P.C., WIDYATMOKO D., YAHARA T. \& K.M. WONG 2019. Progress on Southeast Asia's Flora projects. Gardens' Bulletin Singapore 71(2): 267-319. https://doi.org/10.26492/gbs71(2).2019-02

MÖLLER M. \& Q.C.B. CRONK 1997. Origin and relationships of Saintpaulia (Gesneriaceae) based on ribosomal DNA internal transcribed spacer (ITS) sequences. American Journal of Botany 84(7): 956-965. https://doi.org/10.2307/2446286

MÖLLER M., NISHII K., ATKINS H.J., KONG H.H., KANG M., WEI Y.G., WEN F., HONG X. \& D.J. MIDDLETON 2016. An expansion of the genus Deinostigma (Gesneriaceae). Gardens'Bulletin Singapore 68(1): 145-172. https://doi.org/10.3850/s2382581216000119

MÖLLER M., ATKINS H.J., BRAMLEY G.L.C., MIDDLETON D.J., BAINES R., NGUYEN V.D., BUI H.Q. \& S. BARBER 2018. Two new species of Oreocharis (Gesneriaceae) from northern Vietnam. Edinburgh Journal of Botany 75(3): 309-319. https://doi.org/10.1017/S0960428618000148

NYLANDER J.A.A. 2004. MrModeltest v2. Program distributed by the author. Evolutionary Biology Centre, University of Uppsala.

RANASINGHE S.W. 2017. Molecular species delimitation, taxonomy and biogeography of Sri Lankan Gesneriaceae. Ph.D. Thesis, University of Edinburgh.

RONQUIST F. \& J.P HUELSENBECK 2003. MrBayes 3: Bayesian phylogenetic inference under mixed models. Bioinformatics 19: 1572-1574. https://dx.doi.org/ 10.1093/bioinformatics/btg180

RONQUIST F., TESLENKO M., VAN DER MARK P., AYRES D., DARLING A., HÖHNA S., LARGET B., LIU L., SUCHARD M.A. \& J.P. HUELSENBECK 2012. MrBayes 3.2: Efficient Bayesian phylogenetic inference and model choice across a large model space. Systematics Biology 61: 539-542. https://dx.doi.org/ 10.1093/sysbio/sys029

SWOFFORD D.L. 2002. PAUP*: Phylogenetic Analysis Using Parsimony ( ${ }^{\star}$ and other methods). Version 4. Sinauer Associates, Sunderland, Massachusetts.

TABERLET P., GIELLY L., PAUTOU G. \& J. BOUVET 1991. Universal primers for amplification of three noncoding regions of chloroplast DNA. Plant Molecular Biology 17(5): 1105-1109.

THIERS B. [continuously updated]. Index Herbariorum: A global directory of public herbaria and associated staff. New York Botanical Garden's Virtual Herbarium. Available at: http://sweetgum.nybg.org/ih 
WANG W.T., PAN K.Y., LI Z.Y, WEITZMAN A.L. \& L.E. SKOG 1998. Gesneriaceae. In: WU Z.Y. \& P.H. RAVEN (eds), Flora of China. Volume 18. Science Press, Beijing and Missouri Botanical Garden Press, St. Louis. pp. 244-401.

WOOD D. 1974. A revision of Chirita (Gesneriaceae). Notes from the Royal Botanic Garden Edinburgh 33: 123-205.

\section{Appendix A:}

Characteristics of the Bayesian Inference analysis for the combined ITS and trnL-F data for the relationships among Deinostigma species.

Average standard deviation of split frequencies: 0.009947 Analysis stopped because convergence diagnostic hit stop value. Analysis completed in 6 mins 21 seconds Analysis used 380.80 seconds of CPU time Likelihood of best state for "cold" chain of run 1 was -7709.24 Likelihood of best state for "cold" chain of run 2 was - 7709.59 Acceptance rates for the moves in the "cold" chain of run 1: With prob. (last 100) chain accepted proposals by move

\begin{tabular}{|c|c|c|}
\hline $25.1 \%$ & $(28 \%)$ & Dirichlet(Revmat $\{$ all $\})$ \\
\hline $45.0 \%$ & $(34 \%)$ & Slider $(\operatorname{Revmat}\{$ all $\})$ \\
\hline $24.8 \%$ & $(24 \%)$ & Dirichlet $(\operatorname{Pi}\{1\})$ \\
\hline $29.9 \%$ & $(31 \%)$ & Slider $(\mathrm{Pi}\{1\})$ \\
\hline $24.2 \%$ & $(25 \%)$ & Dirichlet $(\operatorname{Pi}\{2\})$ \\
\hline $27.8 \%$ & $(21 \%)$ & $\operatorname{Slider}(\operatorname{Pi}\{2\})$ \\
\hline $31.7 \%$ & $(27 \%)$ & Multiplier(Alpha $\{2,3\})$ \\
\hline $31.9 \%$ & $(19 \%)$ & Slider(Pinvar $\{1,3\})$ \\
\hline $3.2 \%$ & $(1 \%)$ & $\operatorname{ExtSPR}(\operatorname{Tau}\{$ all $\}, V\{$ all $\})$ \\
\hline $4.5 \%$ & $(7 \%)$ & $\operatorname{ExtTBR}(\operatorname{Tau}\{$ all $\}, \mathrm{V}\{$ all $\})$ \\
\hline $7.1 \%$ & $(3 \%)$ & NNI(Tau $\{a l l\}, V\{$ all $\})$ \\
\hline $7.6 \%$ & $(3 \%)$ & $\operatorname{ParsSPR}(\mathrm{Tau}\{$ all $\}, \mathrm{V}\{$ all $\})$ \\
\hline $26.6 \%$ & $(31 \%)$ & Multiplier(V\{all $\})$ \\
\hline $24.5 \%$ & $(22 \%)$ & Nodeslider(V\{all $\})$ \\
\hline $21.0 \%$ & $(27 \%)$ & TLMultiplier(V\{all\}) \\
\hline
\end{tabular}

Acceptance rates for the moves in the "cold" chain of run 2: With prob. (last 100) chain accepted proposals by move
$24.1 \% \quad(28 \%)$
Dirichlet (Revmat $\{$ all $\})$
$45.8 \% \quad(41 \%)$
Slider(Revmat $\{$ all $\})$
$24.3 \% \quad(31 \%)$
Dirichlet(Pi $\{1\})$
$29.4 \%$
$(24 \%)$
Slider $(\operatorname{Pi}\{1\})$

$\begin{array}{lll}23.2 \% & (31 \%) & \text { Dirichlet }(\operatorname{Pi}\{2\}) \\ 27.1 \% & (23 \%) & \text { Slider(Pi }\{2\}) \\ 32.1 \% & (27 \%) & \text { Multiplier(Alpha }\{2,3\}) \\ 31.4 \% & (32 \%) & \text { Slider(Pinvar }\{1,3\}) \\ 3.0 \% & (4 \%) & \text { ExtSPR(Tau }\{\text { all }\}, \mathrm{V}\{\text { all }\}) \\ 4.5 \% & (7 \%) & \text { ExtTBR(Tau }\{\text { all }\}, \mathrm{V}\{\text { all }\}) \\ 7.0 \% & (7 \%) & \text { NNI(Tau }\{a l l\}, \mathrm{V}\{\text { all }\}) \\ 7.7 \% & (6 \%) & \text { ParsSP(Tau }\{\text { all\},V }\{\text { all }\}) \\ 26.6 \% & (28 \%) & \text { Multiplier(V }\{\text { all }\}) \\ 24.2 \% & (23 \%) & \text { Nodeslider(V }\{\text { all }\}) \\ 21.3 \% & (24 \%) & \text { TLMultiplier(V }\{\text { all }\})\end{array}$

Chain swap information for run 1 :

\begin{tabular}{|c|c|c|c|}
\hline 1 & 2 & 3 & 4 \\
\hline 11 & 0.68 & 0.43 & 0.25 \\
\hline $2 \mid 73791$ & & 0.71 & 0.47 \\
\hline $3 \mid 74312$ & 73845 & & 0.72 \\
\hline $4 \mid 74369$ & 74219 & 74464 & \\
\hline n swap info & rmation & for run & n 2: \\
\hline 1 & 3 & 4 & \\
\hline 11 & 0.67 & 0.43 & 0.25 \\
\hline 2 | 73767 & & 0.70 & 0.46 \\
\hline $3 \mid 74334$ & 74477 & & 0.72 \\
\hline $4 \mid 74180$ & 74114 & 74464 & \\
\hline
\end{tabular}

Upper diagonal: Proportion of successful state exchanges between chains

Lower diagonal: Number of attempted state exchanges between chains

Chain information:

ID - Heat

$$
\begin{aligned}
& 1-1.00 \text { (cold chain) } \\
& 2-0.91 \\
& 3-0.83 \\
& 4-0.77
\end{aligned}
$$

Heat $=1 /\left(1+T^{*}(\mathrm{ID}-1)\right)$

(where $\mathrm{T}=0.10$ is the temperature and ID is the chain number) 